\title{
Abordagem centrada nas pessoas
}

\section{Approach focused on people}

\author{
Roa Ruben \\ Ana Carolina Diniz Oliveira \\ Leonardo C M Savassi \\ Lecticia Cabral de Souza ${ }^{4}$ \\ Ruth Borges Dias
}

\section{Resumo}

A Medicina de Família e comunidade pressupoe um novo marco epistemológico que obriga também o uso de instrumentos e ferramentas que se correspondam com ela. Este modelo de atenção permite levar adiante uma consulta onde estejam presentes todas as categorias nas quais se expressa o processo saúde-doença. A Medicina de Familia pretende combinar ambas visões e para isto oferece elementos para incorporar a moléstia como parte essencial da nossa sistemática de abordagem do paciente sendo o foco principal a abordagem por problemas, que nada mais é que aquilo que preocupa a pessoa, sua família ou o médico, ou a todos, e às vezes haverá moléstia, em outras doenças e em outras tantas ambas coexistirão. Sabe-se que o impacto de um problema de saúde sobre uma pessoa não só afeta a ela, mas também ao seu entorno. Este por sua vez pode atuar como origem ou perpetuador da crise, ou então servir para ajudar na resolução do conflito. Distintas ferramentas servem para o propósito de conhecer o contexto no qual a crise de saúde se desenvolve, tais como: genograma, ciclo vital individual e familiar. Toda vez que duas pessoas se comunicam, o acordo ou desacordo são variáveis possíveis. Na relação médico-paciente isto não é uma exceção. Os valores, crenças, sentimentos e informações de cada indivíduo são diferentes, e não necessariamente médicos e pacientes estão de acordo em vários pontos durante uma consulta. O objetivo é a necessidade de alcançar um mínimo de acordos para que esta consulta tenha efetividade terapéutica, sendo assim importante encontrar um território comum. As relaçòes em geral envolvem poder, cuidado, sentimentos, confiança e objetivos. O objetivo neste tipo de relação deve ser obviamente compartilhado por ambos, e não pode ser outro que o de conseguir o maior grau de saúde para nosso paciente. Assim, nossa especialidade, considerada de baixa complexidade, transforma-se em uma especialidade de alta complexidade cognitiva, não havendo dúvidas que é muito mais fácil manejar um eletrocardiógrafo que uma consulta médica.

\author{
Palavras-chave: Medicina de Família e \\ Comunidade; Processo saúde-doença; Assistência \\ Centrada no Paciente; Relações Médico-Paciente.
}

\author{
Key Words: Family and Community Medicine; \\ Health-Disease Process; Assistance Centered on \\ Patient; Physical-Patient Relations.
}

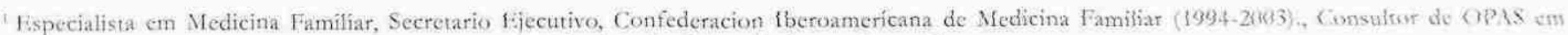
livaluacion de Teenologias Sanitarias. Magister em Epidemiologia, [falta cidade, estado, pais].

Médica de Familia e Comunidade, Prefeitura Municipal de Belo Horizonte, Belo Horizonte, Minas Geriais, Brasil.

Com denador da Residéneia Nédiea em Medicina do Familia e Comunidade, Hospital Püblico Regional de Betim. Berim, Minas Gerais, Brasil.

* Medica de Familia e Comunidade, [falta cidade. estado, pais]

Docente da Unifenas, presidente da AMMFC Gestāo, 2007-2009, [falta, cidade, estado, pais]
} 


\section{Abstract}

Family and community medicine assumes a new epistemological landmark that also provides the use of instruments and tools related to it. This care model permits carrying out a visit where all categories in which the health-disease process is expressed are present. Family Medicine intends to combine both visions and, for such, it offers elements to incorporate disease as an essential part of our patient's approach systematic being the main focus the approach by problems, which is nothing but that which concerns the individual, bis family or the pbysician, or all of them, and at times there will be nuisances while at other times, there will be diseases, and still in other instances, all of them will co-exist. It is known that the impact of a bealth problem on an individual affects not only bimself, but also bis surroundings. In turn, the enviromment around this individual can act as the origin or perpetwator of the crisis, or else serve to belp in solving the conflict. Distinct tools serve the purpose of knowing the context in which bealth crisis is developed, such as: genogram, individual and family vital gycle. Every time two people communicate, the agreement or disagreement generate possible variables. In the physician-patient relationship, this is no exception. Values, beliefs, feelings, and information of each individual are different and plysicians and patients are not necessarily in agreement in several issues during a visit. The objective is the need to achieve a minimum of agreements so that this visit has therapeutic effectiveness, thus being important to find a common territory. Relations in general involve power, care, feelings, trust and goals. The objective in this thpe of relationship must be obviously shared by both and cannot be any other than that of achieving the bighest level of bealth to our patient. So, our specialty, considered of low complexity, becomes a bighly cognitive complexity specialt; and there is no doubt that it is a lot easier to bandle an electrocardiograph than a medical visit.

\section{Introdução}

A Medicina de Família pressupõe um novo marco epistemológico (a epistemologia da complexidade), assim demanda dos profissionais, o uso de instrumentos e ferramentas que se correspondam com ela. Um modelo de atençâo que nos permita levar adiante uma consulta onde estejam presentes todas as categorias nas quais se expressa o processo saúde-doença. Este artigo não tem em si nada de original. Sua virtude reside na possibilidade de sistematizar cada consulta com uma metodologia que nos seja própria, e porque não reinventá-la, já que o que menos pode aspirar de uma especialidade que se baseia em pessoas, famílias e comunidades é permanecer na rigidez do pensamento. Por sua vez, é necessário entender que apesar de existir uma ordem no texto, o mesmo nào necessariamente pode ou deve ser aplicado na consulta real. Esta tem momentos que coexistem temporalmente, e circunstâncias que fazem com que todos os elementos planejados no modelo possam ser levados à prática em uma consulta. Não devemos nos esquecer que o tempo da consulta deve ir além de nosso contato visual com nosso paciente. Em Medicina de Familia, o tempo se vê modificado pela continuidade dos cuidados, portanto, no conhecimento acumulativo que temos de nossos pacientes'.

Para dizê-lo em palavras mais simples, aplicar todos estes instrumentos em uma consulta não apenas é impossível, mas inclusive pode ser impertinente, e o tempo da consulta ser muito maior que cinco ou quinze minutos em medicina familiar, mas que é o tempo durante o qual vamos acumulando conhecimentos a partir da atenção continuada. Talvez. hoje sejam 5 minutos, outro dia trinta minutos de consulta, e será tào importante a freqüência de suas consultas (como é o caso dos hiperutilizadores), quanto a necessidade em alguns casos de convocar as crianças para serem vacinadas ou outras atividades preventivas não são muitas as que realmente são clinicamente efetivas ${ }^{2}$.

Nunca devemos esquecer que a população em geral não gosta de ir ao médico, por mais que nos esforcemos em querer medicalizar todos os aspectos da vida, e deste modo tomar parte de um modelo reducionista e medicalizante, próprio dos países centrais que baseiam sua atenção em pessoas saudáveis, enquanto continentes inteiros como a África vêem morrer sua gente dia a dia, pelo simples fato de terem sido condenados a pobreza e descaso dos poderosos da Terra.

Esta sistematização que aqui se propõe não deve 
afetar a fluidez que deve existir durante o desenvolvimento normal de cada consulta, portanto, múltiplos pontos aqui citados são avaliados ao mesmo tempo, ou através de diferentes processos, às vezes não tão claros como aqui se expõem. Assim, o leitor desprevenido deverá tomar cuidado para nem tudo o que aqui expomos se pode ou se deve realizar, ou talvez, sejam muitas mais as questôes que devemos levar adiante em nosso trabalho.

\section{Moléstia e doença}

Deve-se entender em primeiro lugar a grande diferença que existe entre estes conceitos. Moléstia, ou perturbação (Illness), que constitui a experiência particular que vive cada indivíduo ao adoecer ou sentir-se mall. Ou seja, é o modo singular, único, no qual cada pessoa é afetada pela doença. A moléstia é a construção vital que nossos pacientes realizam acerca de seu mal estar, ou seja, é o modo em que este é vivido.Trata-se de uma experiência única, singular, já que ainda que a moléstia possa parecer igual, por exemplo a dor, a tristeza, nunca saberemos quão semelhante é a dor e a tristeza que nós mesmos sentimos, e portanto transforma uma experiência universal em um sentimento único, que ainda pode ser modificado pela cultura, pelo tempo, nossas experiências e ou nossa ignorância.

A doença (disease) é no modelo biomédico, explicável a partir da fisiopatologia, anomalias estruturais, que definem alterações funcionais, e que se expressam (com maior probabilidade) de uma maneira particular, independente do indivíduo. Há um significado ontológico per se, que são construções mentais, reações probabilísticas derivadas de um modelo bayesiano que nem os médicos em geral conhecem. A doença constitui-se assim em uma construção mental que nós médicos criamos para abordar com maior facilidade os problemas biológicos.

Assim, marcada a diferença, nasce uma relaçào dialógica entre ambos conceitos. A maior parte das vezes, ambas coexistem em uma mesma pessoa, portanto, é impossível separar uma da outra. A Medicina de Família pretende combinar ambas visões e para isto oferece elementos para incorporar a moléstia como parte essencial da nossa sistemática de abordagem do paciente. Em definitivo temos que na Medicina de Familia nossa abordagem é por problemas, que nada mais é que aquilo que preocupa a pessoa, sua família ou o médico, ou a todos, e às vezes haverá moléstia, em outras doenças e em outras tantas ambas coexis. tirão.

A doença tem sido vastamente abordada, e é a linha central sobre o qual se desenvolve nossa formação de graduação na maioria das escolas médicas. A anamnese segue-se o exame físico e eventualmente exames complementares, Junto a isto o médico faz uma lista de diagnósticos diferenciais decidindo-se por algum em particular e dependendo destas decisões prescreverá ou não um tratamento.

\section{A moléstia em transição pode ter distintos estágios}

A não-moléstia: comum entre nossos pacientes nos quais diagnosticamos Hipertensão Arterial, Dislipidemia, ou Diabetes, quando estas estão em seu período assintomático. Nada sentem, portanto, nada thes preocupa. A simples consternação pode vir pela experiència de alguém próximo que tenha padecido de complicações por esta doença. Ou então pela explicação que damos os médicos a fim de conscientizar nossos pacientes da necessidade de cuidados. Nesta etapa é quando devemos ter maior cuidado para que nosso modelo explicativo seja o mais próximo ao do paciente, a fim de nào gerar resistências ${ }^{3}$ Nás debemos tener cuidado em no caer em terrorismo sanitário, asustando com prácticas preventivas de limitada eficácia s promoviendo la medicalizacion". Ambivalência: Caracterizado pela ambivalência de querer saber $\mathrm{e}$ às vezes não querer admitir que algo pode andar mal. Freqüentemente, os pacientes se encontram inertes, e a crença mágica de que são imunes ao males é jogada por terra. Discussão e frustração inicial começam a transformarse em temor e tristeza, enquanto a finitude da existència se fazem presentes.

Desorganização: A incerteza toma lugar, e há reação frente a seus cuidadores, como se fossem pais, mais que pares. Muitos centram em si mesmos e se tornam demandantes. Qualquer alteração no corpo pode ser vivida dramaticamente e associada a doença. Não aceitam seus corpos e a 
Diagrama 1. Doença X Moléstia. Extraído de ROA, R. "Medicina Centrada na Pessoa" III Congresso Mineiro de Medicina de Familia e Comminiade. Belo Horizonte-MG, Brasil, 06 a 10 de Junho de 2007. Palestra.

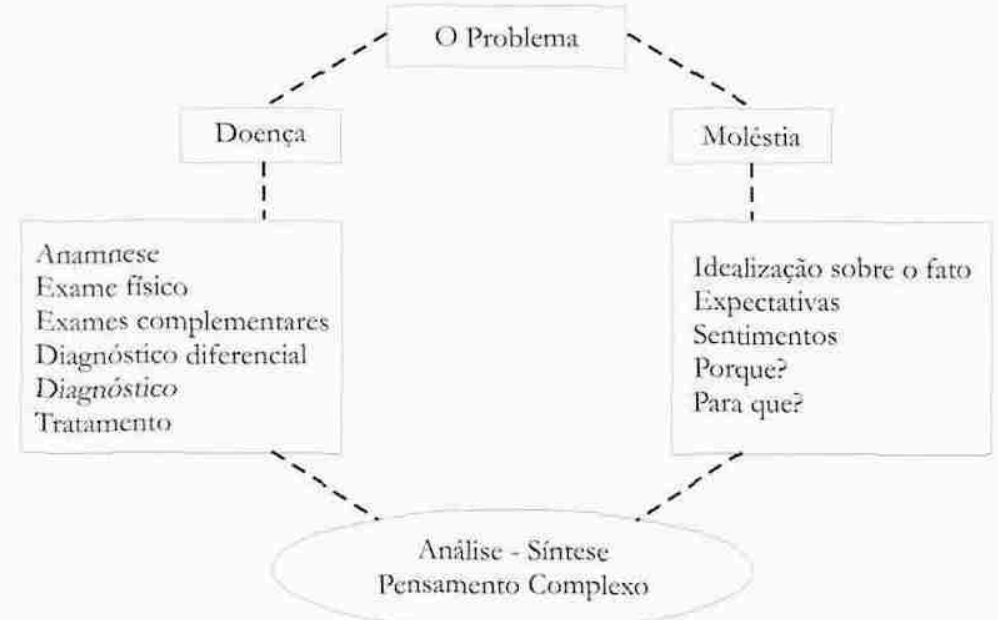

ameaça de uma vida com limitações está presente. É tempo de confusão e vergonha, e a terrível inquietude de não pode controlar sua própria vida. Tanto desconcerto há que não poucas vezes a consulta inicia com um "venho ver como estou", quando na realidade ninguém melhor que ele, ou ela para dizer-nos. Muitos pacientes se rebelam, inclusive contra o tratamento, ao menos como modo de fazer saber que ainda podem controlar algo, ainda que isto seja em si uma conduta auto-destrutiva. Outros se tornam altamente dependentes e as consultas ao médico são muito freqüentes e como médicos não sabemos reconhecer que esta atitude não é esperável (ainda que conveninente para o médico se a consulta é paga). O objetivo é que o paciente recupere controle sobre si mesmo, e o médico seja seu ajudante.

Reorganização: Os pacientes chegam a ela a partir de recursos próprios, familiares e/ ou grupais que the permitam expressar suas próprias forças. A moléstia adquire uma dimensào distinta e a crise é passível de ser vivida como uma oportunidade para a mudança. O paciente e sua família assumem o nivel de responsabilidade que thes corresponde, e procuram o médico como suporte. E este se constitui em um cuidador mais dentro do seu universo.

\section{As dimensões da moléstia}

Assim como aprendemos uma sistemática de revisão da doença, é possível encontrar uma sistemática de revisào da moléstia. Para isto, oferecemos, na forma de critérios mínimos, a seguinte avaliação, a qual não impede que o leitor possa enriquece-la com mais elementos:

Expectativas sobre o médico: o que o paciente espera de nós. Uma simples pergunta no começo pode ser útil: "em que posso ajudá-lo?". Se tivermos uma resposta sempre em mente, e tentarmos nos dar conta da mesma, veremos como o grau de satisfação de nosso paciente será ampliado. Por outro lado, o mesmo permitirá ter uma idéia do que mais o preocupa em relação a sua doença. Procurando diferenciar la demandá-lo que el paciente pide, de làs verdadeiras necesidades do paciente ${ }^{5}$.

Idealização dos pacientes: acerca do que thes sucede. Assim veremos que muitos expressam as causas de seus males atribuída a concepções mágicas ou religiosas, ou então sào racionalizadas como modo de distanciá-las dos sentimentos. A origem é atribuída a fatores externos afim de não se responsabilizar por seu problema ("fumo porque no meu trabalho todos o fazem") ou ainda uma tendência a culpar-se quando nào corresponde.

Sentimentos: Quais são seus medos, como vive o que the sucede. Que sente ele ou sua família. Quão preocupados estão todos. Quem está mais preocupado na casa, etc.

Efeitos sobre a função: como pioram as atividades diárias 
limitadas, e como afetam ao resto da família (não é o mesmo que adoeça um adolescente ou que adoeça a mãe de uma casa que em geral é responsável pelo dia-a-dia ${ }^{6}$

\section{Entendendo a pessoa em sua totalidade}

Sabe-se que o impacto de um problema de saúde sobre uma pessoa não só afeta a ela, mas também ao seu entorno. Este por sua vez pode atuar como origem ou perpetuador da crise, ou então servir para ajudar na resolução do conflito. Distintas ferramentas servem para o propósito de conhecer o contexto no qual a crise de saúde se desenvolve.

- O familiograma ou genograma: que nos permite obter dados não só de predisposição genética, mas também de estrutura e dinâmica familiar, hierarquias e coalisões

Este quadro foi tirado (modificado) do livro Genogramas, de McGoldrick ${ }^{8}$. Esta família foi escolhida por ser uma família mais que conhecida em quase todo o mundo ocidental. Entretanto, por ser um livro um pouco antigo, faltam alguns fatos relativamente recentes no mesmo. A família Kennedy é famosa pela morte de JFK, mas também pela morte violenta de seu irmão Robert em 1968. Mas tão interessante é o fato de que a violência não só acompanhou esta geração, onde o irmão mais velho de JFK morreu durante a II Guerra Mundial, mas que persistiu, inclusive com seu irmão Tedd (senador vitalício do império), que meses depois sofreu um acidente que quase the custa a vida (e the custou sua eventual carreira a presidência), quando seu carro caiu em uma ponte, sendo acompanhado por sua secretária.

Pouco conhecido também é o fato de que no mesmo dia que JFK morreu, sua irmã Pat se separa de seu esposo. O fato que Kathlenn, outra de suas irmàs, distanciada de sua mãe, teve um acidente aéreo em 1948, onde faleceu seu esposo. E os filhos desta família, das quais Tedd se fez responsável praticamente por toda ela após a morte de Bob, a maioria teve episódios de violência, ações judiciais por delitos, mortes em acidentes de ski, alcoolismo, uso de drogas ilícitas e talvez a morte mais conhecida, a do próprio filho de JFK (John-John) em um acidente de avião.
Poder, relações extraconjugais por toda a parte, drogas, violência, sexo, tudo como para escrever um livro de uma das famílias mais glamorosas dos EUA, que parecem seguir um padrão que engloba várias geraçòes e talvez ainda nào tenha terminado. ${ }^{9}$

- O ciclo vital familiar a individual no qual se encontra nosso paciente e sua família ${ }^{10}$

- Técnica de círculos: tem como objetivo avaliar sob outra perspectiva a dinâmica familiar de nosso paciente, ajudar ao paciente a ver relação e solução antes não observadas, predizer as conseqüèncias da mudança, ajudar a transferir o foco de atenção do indivíduo e seus sintomas para uma perspectiva familiar.

- A valorização das funções primárias de nosso paciente: alimentação, sexualidade, catarse, sonho.

- A experiência prévia de nosso paciente com o sistema de atenção da saúde. Saber quem foi o médico dele é de grande valor, já que nos dìrá que coisas está buscando e não encontra.

- Linhas da vida: que nos permite visualizar em paralelo como desenvolveu os marcos biográficos maiores de nossos pacientes, vinculados ao resto da familia, a amigos íntimos ou acontecimentos sociais relevantes.

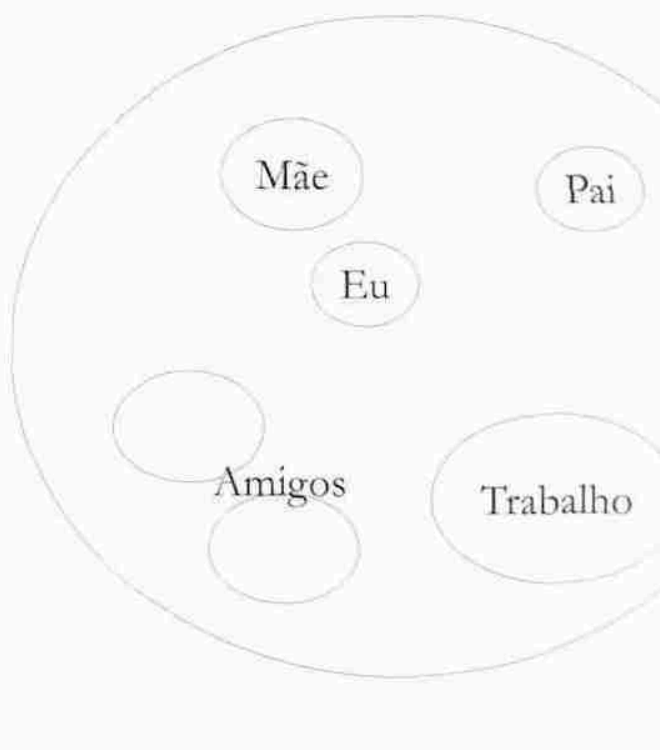


Diagrama 2. A familia Kennedy - Mudanças de vida, transiçòes e tramas.
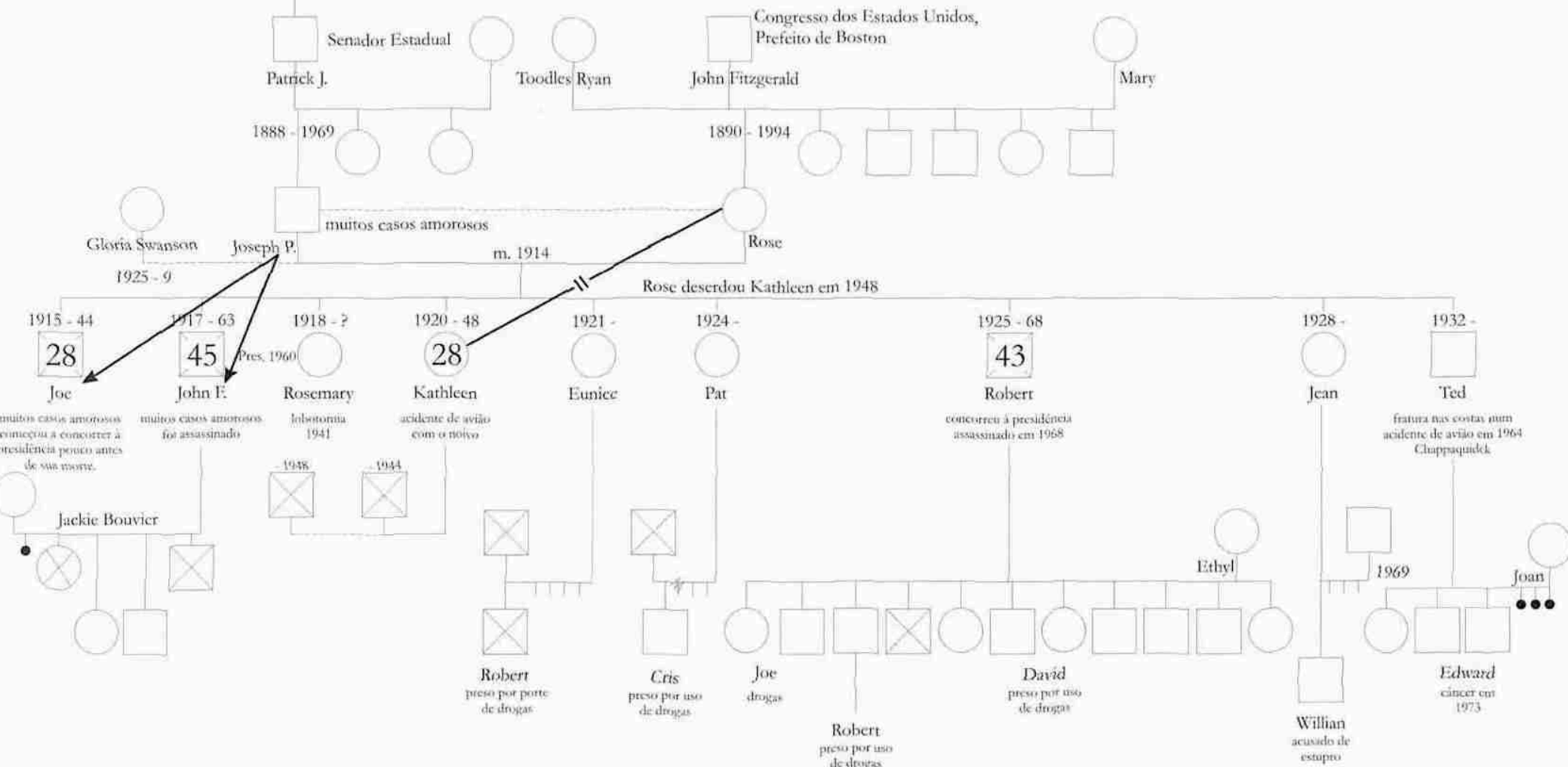

造 
Diagrama 3. A família de Jacqueline Kennedy Onassis - Continuação do ciclo de desastres.
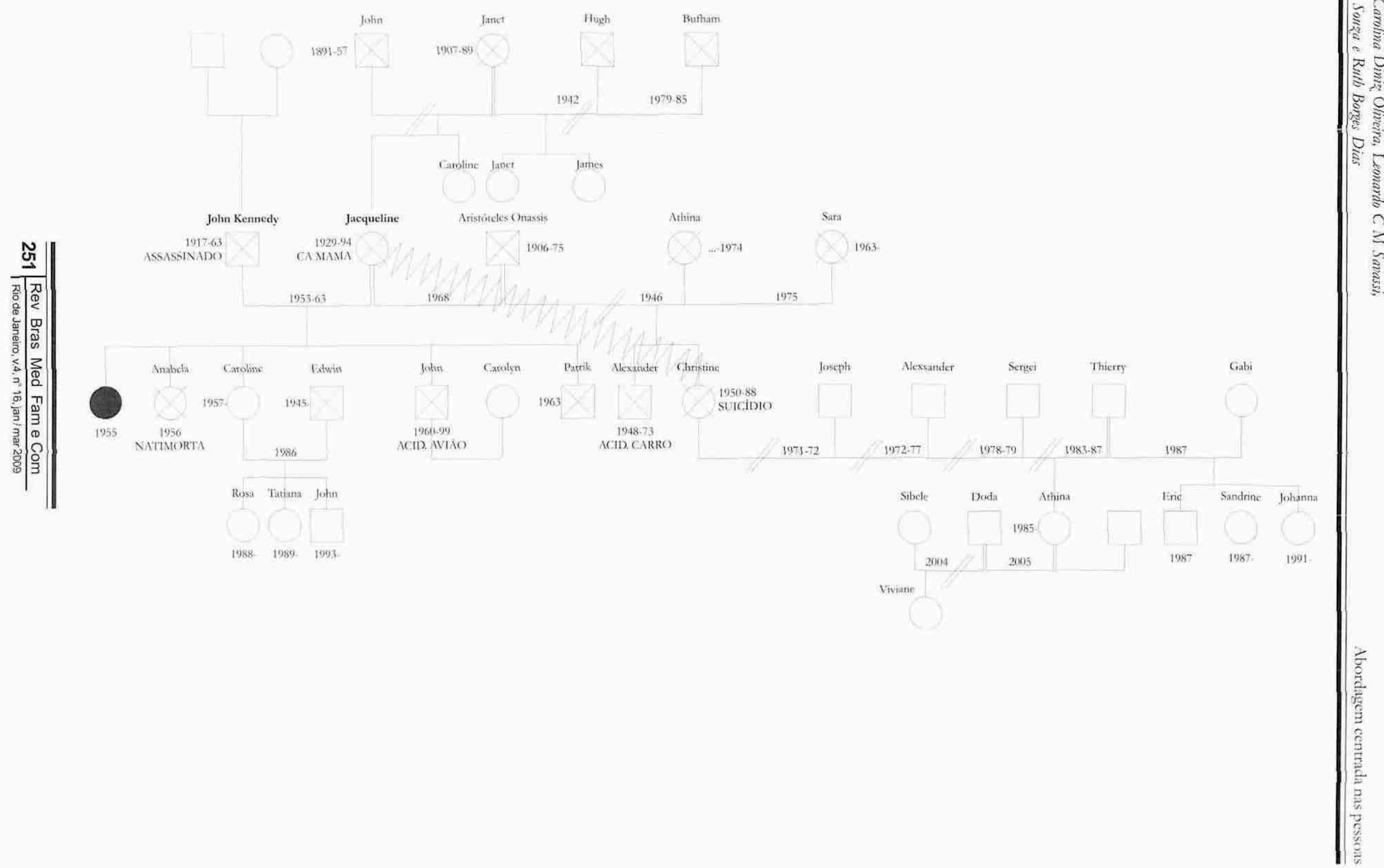
Diagrama 4. Ciclos Vitais

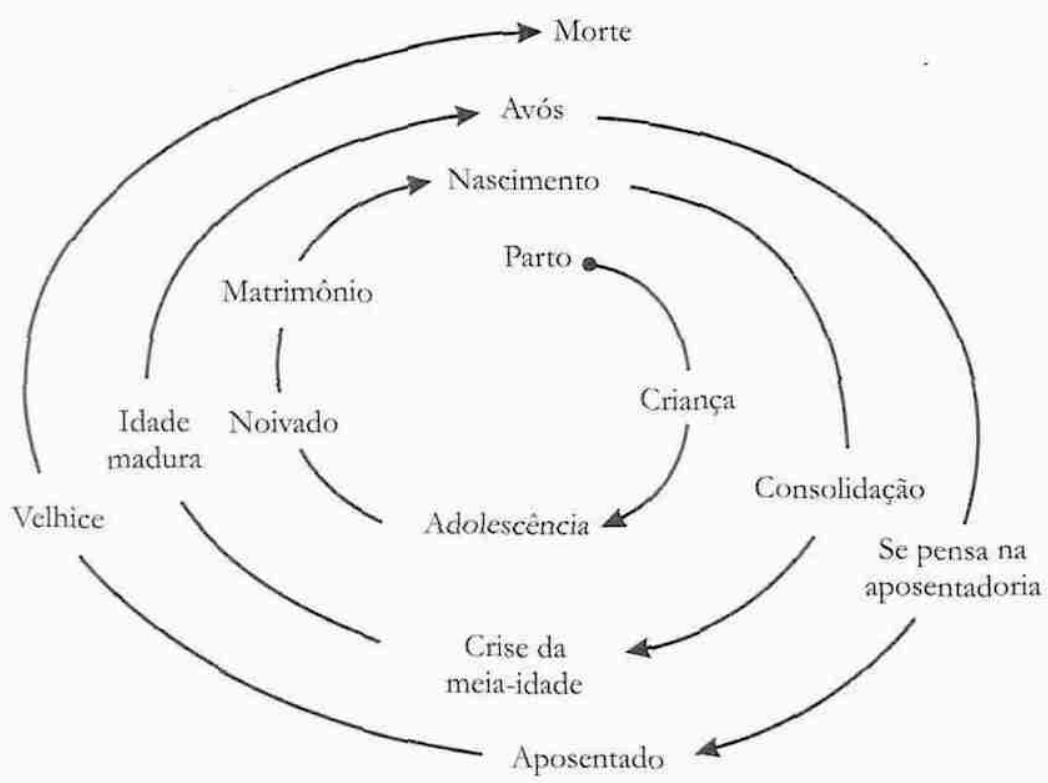

- Influências culturais: Qual é sua concepção da saúde e da doença, quais são seus valores, sua religião, suas crenças, sua moral, nivel de instrução.

- Suporte: está amplamente demonstrado que quanto maior for o suporte familiar ou o círculo íntimo de uma pessoa, menor possibilidade de adoecer, e em todo caso também maior possibilidade de recuperaçăo ${ }^{11}$. Alguns avaliam isto através da escala de Apgar Familiar:

Tamanho

Densidade

Composição

Multiplicidade

Reciprocidade

Qualidade

Homogeneidade

- Nivel de conflitos: valorizados através de escalas como por exemplo a de Holmes ${ }^{12}$.

Problemas que se apresentam

Função e normas

Afeto

Comunicação

Tempo no Ciclo vital familiar

Indisposição ou doença

Comunidade

Ambiente
- Existem tabelas semelhantes que levam em conta fatores culturais locais e sócio-econômicos.

- Nível sócio-econômico: uma infinidade de estudos vinculam o menor nível sócio-econômico a maiores probabilidades de adoecer e morrer, para grande parte dos problemas de saúde. O nível de pobreza se refere basicamente a pobreza estrutural. ${ }^{13}$

- Situaçào ecológica: reconhecer o habitat diário em que vive nosso paciente. Se há contaminantes, se tem água potável, se trabalha em um edifício sem luz natural durante todo o dia, etc. ${ }^{14}$

Todos estes elementos nos servirão para ter um conhecimento maior sobre quem nos consulta, que podem servir para a consulta atual, ou servir de base para o desenvolvimento de guias antecipatórias (preventivas).

\section{Encontrando acordos para o cuidado.}

Toda vez que duas pessoas se comunicam, o acordo ou desacordo são variáveis possíveis. Na relação médicopaciente isto não é uma exceção. Os valores, crenças, sentimentos e informações de cada indivíduo são diferentes, e não necessariamente médicos e pacientes estão de acordo em vários pontos durante uma consulta. O objetivo é a necessidade de alcançar um mínimo de acordos para que 
esta consulta tenha efetividade terapêtica, sendo assim importante encontrar um território comum.

\subsection{Definição do problema.}

É inerente a nossa natureza tentar nomear e rotular os acontecimentos, lhes outorgando uma entidade que fica associada a uma explicaçào específica das causas que a originaram, perpetuam ou modificam. Quando há um problema de saúde, tanto o médico como o paciente, tentam nomeá-lo e dão uma explicação que dê sentido a sua experiência. A dor articular pode ser explicada pelas mudanças de tempo, ou pela possibilidade de uma Artrite Reumatóide. Neste caso, médico e paciente devem buscar um denominador comum que thes permita trabalhar em conjunto. Parte desta linguagem está constituída por uma abordagem baseada em problemas. Se a diferença é persistente não haverá espaço para efetividade no tratamento, e a relação médico-paciente se deteriorará. A explicação deve ser consistente para a visão global de cada um. O médico não deve impor sua opinião, e muito menos ignorar a opinião errada do paciente. ${ }^{15}$

Fisher e Ury ${ }^{16}$ descreveram princípios de negociação que dão ferramentas de trabalho para quando se apresentarem situações de dissidências importantes. As quatro táticas básicas deste enfoque são:

1. Separar a pessoa do problema. Quando bem sucedida, atacase o problema e não a pessoa que tem o problema.

2. Focalizar interesses e não pontos de vista. As pessoas tendem a defender seu ponto de vista sob qualquer circunstância, como se tratasse de uma questão pessoal, e com freqüência os interesses se perdem nesta discussão.

3. Gerar várias possibilidades antes de decidir o que fazer. $\mathrm{E}$ necessário ser criativo e buscar múltiplas opções, evitando cair na emotividade que inibe este processo.

4. Usar o critério objetivo para julgar una solução. É mais que confrontar uma opinião pessoal com outra.

Este modelo de Fisher e Ury tem sido refutado por ter uma concepção mais pertinente para situações jurídicas, sendo o resultado final mais semelhante a uma sentença que a um acordo. Existem outros modelos como a mediação transformativa, baseada na mudança para que os acordos sejam duradouros; os modelos do círculo narrativo ${ }^{17}$ que tratam de reconstruir uma história (narração), em conjunto, a partir de um processo de colaboraçào nos pontos concordantes. Cremos que este último modelo parece mais pertinente em nossa prática clínica.

\subsection{Definindo as metas do tratamento do problema e o cuidado com a saúde.}

O tratamento é outro ponto no qual pode-se discordar. Os pacientes podem pedir antibióticos para uma Angina Viral, e o médico enfrentar situaçòes tais como: ter de dizer não e explicar o porquê (nosso paciente vai comprar o medicamento na farmácia), que o médico saiba que se não der medicamento ao paciente esse vai sentir que não foi the dada atenção. $\dot{E}$ importante explicat ao paciente quando houver a incerteza do diagnóstico e the for solicitado que volte no dia seguinte (a insatisfação é de ambos), etc. Em todo caso é necessário valorar adequadamente o significado da doença, o risco da enfermidade para cada paciente em particular, e o efeito que o problema, o tratamento e o não tratamento geram no lar.

É necessário que o médico não perca de vista o senso de oportunidade para dar indicações, nem tampouco deixar de focalizar quando a quantidade de problemas se avoluma.

As metas devem se basear nas expectativas tanto do paciente como do médico, a fim de assegurar um bom cumprimento das mesmas. $\mathrm{O}$ paciente deve conhecer os prós e contras de cada tratamento, e sentir-se parte da decisão. Quando receber indicaçòes claras de como o mesmo deve ser administrado e a orientações antecipatórias para eventuais reações adversas, ser capaz de controlá-las positivamente.

\subsection{Definindo o papel do paciente e do médico.}

O papel de cada um dos participantes também deve ser definido, explícita ou implicitamente, afinal de contas são necessários dois para dançar um tango. Os pacientes requerem muitas vezes, uma atitude paternalista e 
onisciente dos médicos, outras vezes uma atitude flexível e indulgente com suas negligências, e em outras uma atitude compreensiva e explicativa ao invés de uma atitude tecnicamente correta. Alguns médicos preferem pacientes submissos e são resistentes a explicar o problema. Outros são muito abertos, e alguns se atrevem a demonstrar suas próprias dúvidas, o que em si é bom desde que não transmita uma imagem de insegurança frente ao paciente. Outros sào capazes de ser flexíveis ante diferentes pacientes, $\mathrm{o}$ ante um mesmo paciente em distintas circunstâncias.

Em todo caso o conhecimento acumulativo que se tem do paciente é uma ferramenta útil que permite moldar e acomodar os passos da dança. De todo modo, o que não é negociável é o compromisso total que o médico deve assumir frente a cada pessoa, em toda circunstância.

O processo de encontrar um terreno comum entre o médico e a pessoa: o mesmo começa quando se programam metas e se definem papéis na relação. $A$ discussão deve continuar dando a oportunidade a pessoa de perguntar, mostrar atitudes e acalmar suas ansiedades. O objetivo máximo seria poder explicitar todas estas tarefas em conjunto.

Em resumo, o desenvolvimento de um manejo efetivo do plano de tratamento requer que o médico e o paciente realizem um pacto entre as áreas:

1. Origem do problema

2. Metas e prioridades do tratamento

3. Papéis do médico e do paciente

Freqüentemente, os médicos e os pacientes possuem divergentes pontos de vista nas diferentes áteas (não esqueçamos a assimetria de informação, cultural, e ás vezes de classe que existem). O processo de encontrar um campo de trabalho em comum para uma solução satisfatória do problema não consiste em outra coisa que pactuar ou negociar, com a plasticidade de duas mentes, no contexto de uma familia impregnada por uma cultura singular. Não se deve esquecer nunca que para este objetivo o médico deverá ter em mente o significado que a doença tem para este paciente, a partir do momento em que a pessoa reconhecer a implicação de sua enfermidade em seu processo vital.

\section{Incorporando a prevenção na prática clínica.}

Os cuidados preventivos em Medicina Familiar são inerentes a prática. Não existe um momento para a prevenção e outro momento para a assistência. Um e outro constituem o mesmo espaço. Toda consulta deve ser tomada como uma oportunidade para exercer ações de prevenção. Mas, apesar das características de continuidade que abrangem nossa prática, isto não pode ser desculpa para prorrogar uma ação para o futuro, se esta não está contra-indicada no momento. Isto é um imperativo ético em nossa prática. No resto da obra podemos ler os aspectos gerais e particulares que permitem valorar as distintas práticas preventivas que pomos em jogo, a partir dos critérios de Wilson y Jugner ${ }^{18}$, critérios que na maioria das vezes não se cumprem. Neste artigo exporemos as circunstâncias que permitem facilitar a aplicabilidade destas medidas.

A incerteza, entre outros fatores, dada pela realidade em que os pacientes que procuram o serviço de atenção primária, muitas vezes, em etapas mais precoces de seus problemas, interfere na maioria das vezes, na possibilidade dos médicos cometerem o maior número de erros ou omissões nos aspectos da prevenção secundária e terciária neste sentido.

A promoção de saúde é definida como o processo de capacitar as pessoas para controlar e melhorar sua saúde e a prevenção primária propriamente dita é dividida em: - Abordagem sobre a base da redução do risco, diminuindo os fatores que se reconhecem como potencialmente causais ou predisponentes.

- Detecção precoce da doença (screening ou case finding). O enfoque de prevenção primária deve sempre considerar o indivíduo em sua totalidade, e na relação com sua família. É necessário ter em conta, ao menos 6 componentes no mundo de nosso paciente:

1.Doença atual e prováveis doenças;

2.Experiência do paciente sobre a saúde e a doença: é necessário indagar os sentimentos da perda do estado de saúde e da perda do controle, na medida em que possam 
afetar sua conduta. Existem estudos que correlacionam significativamente o que o paciente manifesta como saúde e seu estilo de vida. Aqueles que consideram a saúde como algo mais que a ausência de enfermidade tendem a assumir um compromisso maior nas tarefas de promoção. É necessário ter uma idéia clara do nível de alarme que cada paciente tem para distintos sintomas. As estratégias de promoção são adotadas somente se percebidas como úteis, e quanto maior é o obstáculo para alcançar os níveis de saúde menor é o nível de prevenção alcançável. Quanto mais orientada é a experiência do paciente para a doença, mais solicitará do médico o seu caráter reabilitador. Se o paciente é pouco susceptivel a adoecer, se consciente dos benefícios da promoção e prevenção, requisitará mais como um educador ou facilitador de saúde.

3. As potencialidades do paciente para a saúde: a idade, o gênero, as condições genéticas e ambientais, os valores pessoais definem o potencial de cada indivíduo. A auto-eficácia é a capacidade do paciente de cumprir as metas que se propõe, a mesma está influenciada pela perseverança para manter uma conduta, os recursos próprios e familiares e as crenças individuais que dirigem a conduta em direção às metas desejadas. A auto-eficácia e o nível de saúde têm-se mostrado os preditores mais importantes na promoção de saúde. Não deve omitir o viés de que aqueles que mais solicitam práticas preventivas são em geral os que menos necessitam.

4 O contexto do paciente: a importância dos grupos primários já foram ressaltadas. A conduta do médico, e em especial o uso do conhecimento acumulativo que tem o paciente, é outro poderoso preditor para conseguir práticas preventivas eficazes.

5.Relação médico-pessoa: Pommerenke e Dietrich ${ }^{20}$, Quill , Sanson-Fisher e Maguire, revelam que a atitude do médico somado a uma pobre capacidade comunicativa são os obstáculos mais importantes para o cumprimento das práticas preventivas.

6. Incentivos e obstáculos: que a estrutura e a qualidade dos processos estejam assegurados a partir da garantia dos recursos mínimos para executar as ações requeridas.
Em definitivo, o sucesso de levar a cabo uma ação de promoção ou prevenção será dado pela predisposição positiva do médico para isto, assim como um correto diálogo entre pares, onde o médico avalia os valores pessoais, as necessidades, motivaçòes e expectativas do paciente. Este é um processo de ensino e aprendizagem, onde deve-se explorar diferentes estratégias a fim de cumprir o objetivo. O papel de suporte toma parte também deste processo: ouvir, ter empatia, apoiar mudanças de perspectivas através do discurso racional, tomar suas crenças (mesmo as de caráter mágico). Qualquer instrumento deve ser utilizado a fim de fazer efetivo o exercício da prevençào em cada consulta.

A American Task For Preventive Service, em Canada, discute a efetividade de muitas das práticas preventivas $^{21.22} \mathrm{e}$ em muitos casos também a medicalizaçào que tais práticas trazem emparelhadas 14. Esta crescente medicalização das sociedades ocidentais é parte de um tema muito mais complexo que autores como Juan Gervás está analizando. Sem contar com outros como Miguel Jara ${ }^{23}$, Starfield \& Gervas ${ }^{24}$, Dough Bremmer ${ }^{25}$, etc. Tema que sem dúvida merece um artigo além deste. Mais o conceito de prevención cuaternaria debe ser incorporado a nuestra práctica clínica (primum non nocere). Hay un texto de Juan Gervas que se refiere exclusivamente a esto.....no recuerdo cual ya que surgió de discusiones en el grupo de clasificación de enfermedades CIAP2 del que Juan es integrante. ${ }^{26}$

\section{Melhorando a relação médico-paciente.}

As relaçòes em geral envolvem poder, cuidado, sentimentos, confiança e objetivos. O objetivo neste tipo de relação deve ser obviamente compartilhado por ambos, e não pode ser outro que o de conseguir o maior grau de saúde para nosso paciente.

Uma boa relação terapéutica deve fundamentarse e manter-se em atributos tais como a empatia, congruência, respeito, atitude positiva, cuidado e interesse pelo outro, confiança mútua e a facilidade de aceitar as diferenças quando se compartilha um objetivo. 


\section{O Poder.}

é claro que existe uma relação assimétrica entre as partes. Isto não é bom nem ruim em si. O ponto é que esta assimetria (baseada na formação e informação que possui o médico) implique em um processo no qual esta não seja utilizada para criar distâncias. O papel aqui é o de tradutor do conhecimento médico ao nosso paciente. O papel de explicar, aplicar e implicar o cuidado da saúde ao outro em seu processo de cura. Em suma, um papel de facilitador para expressar as potencialidades de saúde de cada pessoa. O poder médico tem sido criticado indiscriminadamente e não por falta de razões. Mas a opção contrária, que é despojar-se, não parece ser uma opção viável para a prática clínica. Pessoas procuram uma outra pessoa quando percebem que esta pode ajudar, ou seja, lhe está concedendo determinado poder, sendo isto por fim necessário. Talvez a pergunta que se deve fazer aqui é se algum de nós iria consultar-se com um médico que consideramos saber menos que nòs... Evidentemente, não. Buscamos a confiança, mas também, acreditamos que ele sabe coisas que não sabemos. Pensamento mágico ou não, o poder é uma realidade da qual não se pode fugir, e não se trata de destruí-la, mas de convertê-la em um poder que esteja a serviço do povo, não dos médicos e nem sequer da ciência, simplesmente um poder a serviço das pessoas.

\section{O Cuidado.}

Implica em um compromisso total com o paciente. Nos foi ensinado a não nos envolvermos, tão só cognitivamente. Isto nos coloca nas funções de observadores e prescritores. Um lugar no qual o compromisso é limitado. O compromisso implica riscos (compartilhar o sofrimento) tempo e esforço; portanto nos é indicado durante nossa formação, nosso autocuidado ${ }^{27} 1$. Não obstante, isto é uma limitação para criar uma atitude de empatia, congruència e interesse pelo outro e, portanto afeta nossa relação, e conseqüentemente nossa eficácia terapêtica. Este cuidado deve ser equilibrado, não tão distante como o que exercemos diariamente, nem tão próximo que nos leve a superproteção do paciente. $\mathrm{O}$ autoconhecimento é uma grande ajuda para buscar o ponto certo.

\section{Tratamento.}

Nem sempre curar o corpo implica curar a pessoa; este último implica recuperar a sensação de conexão, imunidade e controle perdidos. Não se alcança um êxito biológico se o indivíduo inteiro não tenha sido recuperado. Em inglês, as palavras curar, saúde e integridade reconhecem uma raiz comum que deveríamos recordar em cada momento (heal, health, whole).

\section{Autoconhecimento.}

$O$ atuar na atenção e o reconhecer o impacto que o mesmo tem sobre o paciente e sobre si mesmo deveria constituir uma prática habitual em nosso trabalho. Balint ${ }^{28}$, Bowen $^{29}$ e Rogers ${ }^{30}$ têm aproximado diferentes propostas que podem nos servir na prática diária. Significa entender nossas fortalezas e deficiências, valorizar nossas emoções e valores e como eles são postos em jogo em cada consulta. São a base de uma relação honesta, empática e sensível para com nossos pacientes. Esta interação que modifica as condutas dos atores durante uma entrevista é denominada como "segunda cibernética" por múltiplos autores ${ }^{31}$.

\section{Transferência e contra-transferência.}

Estes termos extraídos da psicanálise não fazem mais que reconhecer que tanto os pacientes como os médi$\cos$ (quase humanos que somos), projetamos de modo inconsciente vivências, crenças e emoções adquiridas com outro significado em relações prévias, ou medos ainda futuros. Considerar no paciente estes processos, a partir do autoconhecimento, nos permitirá reconhecer dificuldades que às vezes sobrevivem com determinado tipo de pacientes, e evitar distorções em nossa avaliação clínica, ou impedir

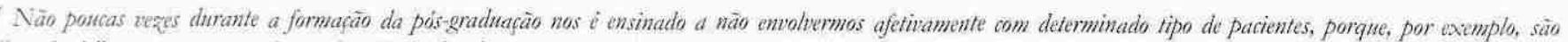
"terminais" esua morte nos fará sofrex. Por falta de sorte, por várias vezes não temos de fato tais conselhos. Cada morte on fracasso terapêntico hos machucam e sezue macbucando. Acreditamos que o dia que isso deixar de suceder seguramente estanmos mais tranqüilos, porém distantes do motivo que nos impulsiona a ser médicos
} 
que a negligência se apodere de nós, quando, por exemplo, desenvolvemos mecanismo de rejeç̧ão a um paciente.

\section{Como exercer uma prática realista.}

É. comum escutar sobre a impossibilidade de exercer um modelo completo em um breve lapso de 15 ou 20 minutos, que é o tempo que em geral nos é atribuído para cada consulta. Esta é uma discussão universal. Nos EUA, consultas deste tipo tem sido mensuradas em 30 minutos, enquanto no Canadá, em 9 minutos, e assim poderíamos seguir com os exemplos, Espanha reclama ao menos 10 minutos por consulta. Talvez o mais importante é que uma consulta deste tipo não pode ser vista de forma descontextualizada do que é a nossa especialidade. A continuidade dos cuidados, a integralidade e a afirmaçâo da saúde nos são inerentes. Estas características fazem com que o conhecimento acumulativo dos pacientes seja uma ferramenta mais que poderosa para suprir o escasso tempo de que se dispõe, ainda que este for delimitado em 2 horas.

Devemos ser realistas e práticos para a hora de exercer nosso modelo de atenção. Os recursos são limitados para todos; o tempo de nossos pacientes não é eterno; nossas famílias reclamam mais tempo com elas; os administradores (gestores) nos pedem que cuidemos dos recursos; a sociedade, que cuidemos de sua saúde. Apesar de cada um parecer buscar objetivos distintos, nenhum deles é necessariamente incompatível com o resto.

Toda nossa experiência deve ser posta em jogo em cada consulta. A epidemiologia clínica e a tomada de decisões nos permitem hoje obter ferramentas que respondam a muitas demandas com maior pertinência e concordância em termos de eficiência e não apenas em termos de custo/benefício, mas também de risco/benefício. ${ }^{32,33,34}$. É necessário entender a concepção de "custo da oportunidade". É o que hoje desperdiçamos (tempo ou dinheiro) em uma prática inútil e não poderá ser utilizado em uma prática eficaz. Este critério é atacado por alguns medicos, citando que a única coisa que se tenta é produzir maiores benefícios ao sistema. Nada mais distante da realidade, já que os sistemas de saúde, e em particular os privados, têm estruturas e processos suficientemente idòneos como transferir qualquer excesso de gastos aos próprios usuários. Portanto, não é pela pressão dos administradores que devemos gerenciar adequadamente todos os recursos que dispomos, mas pelas pessoas, que é, em definitivo, quem sempre (em qualquer sistema de saúde que falarmos) suporta financeiramente o custo da atenção à saúde. Dessa forma, seus recursos devem ser cuidados.

É necessário sermos realistas com nossos tempos durante a consulta e nos treinarmos constantemente para conseguir a maior quantidade de resultados possíveis. Mas também, nos nossos momentos de estudo, quando chega nossa hora de escolher o que ler, portanto o conhecimento da Medicina baseada em evidèncias que nos permitirá otimizar nosso tempo. ${ }^{35}$

É necessário sermos realistas e entendermos que a prática individual, assim como, a abordagem individual das pessoas, são coisas do passado.

Hoje o trabalho em equipes é muito valorizado e a colaboração, a coordenação e a cooperação com os outros integrantes da equipe de saúde é inevitável para um desempenho eficaz, efetivo e eficiente a fim de alcançar o objetivo ainda pendente. A saúde é composta não apenas por nossas ações sanitárias, mas também por nossa relação com nosso ambiente sócio-cultural e nosso meio ambiente. Da mesma maneira a abordagem individual também descontextualizada da família tem uma alta implicação na morbimortalidade, assim como na qualidade de vida. Nossos "pacientes" são parte de uma familia, e recordar esta realidade ajuda a praticar medicina do século XXI mais distante do pensamento Flexneriano ${ }^{36,37,38,39}$.

Assim, nossa especialidade, considerada de baixa complexidade, transforma-se em uma especialidade de alta complexidade cognitiva, não havendo dúvidas que é muito mais fácil manejar um eletrocardiógrafo que uma consulta médica. E no caso se alguém tem dúvidas sobre algumas das ações que devemos realizar diariamente, e nos recordar que somos especialistas em nada, deixemos dá-lo a razào e convidá-lo a observar o seguinte quadro e repensar se o exercício da Medicina baseada em Pessoas se trata de um 
Diagrama 5. Original proveniente de Manuel Galvez Ibañez - Granada - Espanha ${ }^{22}$

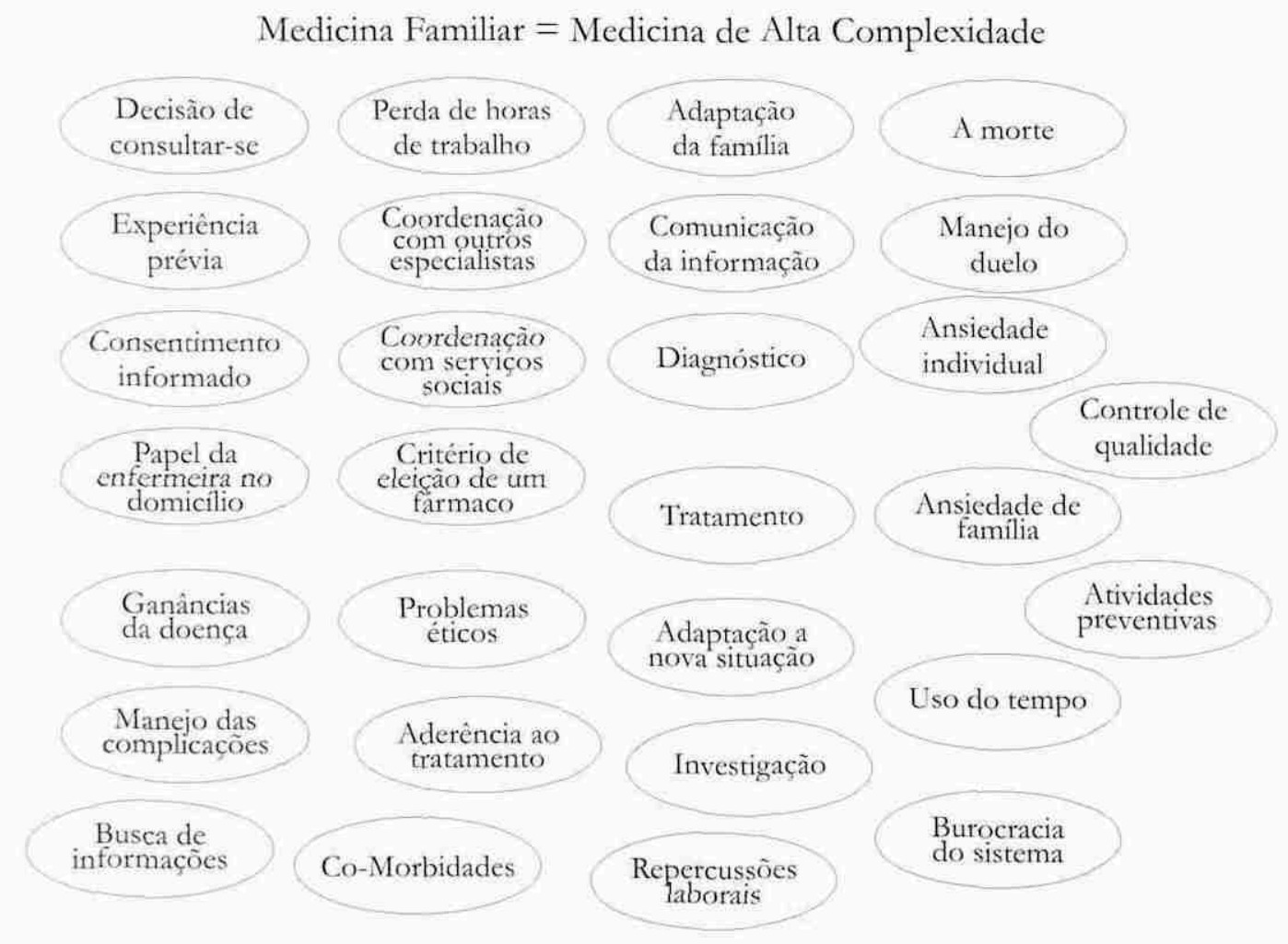

processo de baixa complexidade.

\section{Referências}

1. Roa R, Ruiz Morosini ML, Siede JA. Medicina Familiar: Hacia un nuevo modelo de atención de la salud. Buenos Aires: Akadia; 1997.

2. Galbe Sánchez-Ventura J. ¿Son eficaces las revisiones de salud de los niños. Evid Pediatr. 2008; 4: 47.

3.McWhinney. IR. An introduction for Famillly Medicine. United Kingdom: Oxford University Press; 1981.

4. Starfield B, Gervas J. The concept of prevention: a good idea gone astray? J Epidemiol Community Health. 2008 Jul; $62(7): 580-3$.

5. Revilla L de la, Rios A de los. Problemas psicosociales: factores causales. Repercusiones clínicas y familiares. En: Revilla L de la. Manual de Atención Familiar.. Granada:

Fundación para el Estudio de la Atención a la Familia; 1999. 6. Stewart M, Brown JB, Weston WW, McWhinney IR, William
CL, Freeman TR. Patient Centered Medicine. Transforming the Clinical Method. Thousand Oaks, CA, EEUU: SAGE Publications; 1995.

7. Rakel RE. Textbook of Family Medicine: Text with CDROM (Textbook of Family Medicine) (Hardcover)

8. McGoldrick M, Randy G, Petry S. Genograms: Assessment and Intervention. 3rd Edition (Norton Professional Books). [falta local, ano]

9. Dias Ruth B. Genograma. Jornal InterAtivo. AMMFC. 2006; II ( 5).. Disponível em http://www.smmfc.org.br/ interativo0602.pdf [acesso em 10/09/2007].

10. Carter B, McGoldrick. The Expanded Family Life Cycle: Individual, Family, and Social Perspectives. $3^{\text {rd }}$ Edition. An Allyn \& Bacon Classics.

11. Rakel IR.. Ibidem. Texto citado previamente. [referência precisa ser retirada, não tem informação nenhuma sobre]

12. Farfán S G, Romero Pamg, Hernández GJA. Programa De Actualización Continua En Medicina Familiar. Libro 1. 
Intersistemas; 1995.

13. Shi L, Starfield B, Politzer R., Regan J. Primary care, selfrated health, and reductions in social disparities in health. Health Services Research. 2002; 37: 529-550

14. Lalonde M. A new perspective on the health of Canadians. A working document. Ottawa: Government of Canada; 1974.

15. McWhinney IR. Ibidem. referência precisa ser retirada, não tem informação nenhuma sobre]

16. Fisher R, Patton BM, Ury WL. Getting to Yes: Negotiating Agreement Without Giving In Hardcover; 1992.

17. Sarakov. Buscando cita, Circulos narrativos. No encuentro el libro asi que mejor sacar la cita. [referência precisa ser retirada, não tem informação nenhuma sobre]

18. Wilson JMG Jugner G. Principles and practice of screening for disease. Geneva: WHO; 1968.

19. Autoeficacia en promoción de la salud (cual es la cita?) [referência precisa ser retirada, não tem informação nenhuma sobre

20. Pommerenke FA, Dietrich A.Improving and maintaining preventive services. Part 1: Applying the patient path model. J Fam Pract. 1992 January; 34(1): 86-91.

21. http://wwwahrq.gov/clinic/USpstfix.htm. |referência precisa ser retirada, não tem informação nenhuma sobre] 22. Canadian Task Force on the Periodic Health Examination: The periodic health examination. Can Med Assoc J 1979; 121: $1193-1254$.

23. Miguel Jara. Traficantes de Salud. Barcelona: Icaria; 2007. 24. Starfiel B, Gervas J. Ibidem Texto citado. referência precisa ser retirada, não tem informação nenhuma sobre]

25. Bremner JD. Before You Take that Pill: Why the Drug Industry May Be Bad for Your Health. USA: Penguim Books; 2008.

26. Gervas J. Malicia Sanitaria y Prevencion Cuaternaria. Juan Gervas. Gazeta Sanitaria. Bilbao. España, 2006.

27. Roa R, Ruiz Morosini M, Siede J. Capitulo 1. Texto ya citado. referência precisa ser retirada, não tem informação nenhuma sobre]

28. Balint M.The Doctor, His Patient and the Illness.. USA:

Paperback; 2003.
29. Bowen M. Family Therapy in Clinical Practice. USA: Paperback; 1994.

30. Rogers C. Client-Centered Therapy: Its Current Practice, Implications, and Theory. USA: Paperback; 2003).

31. Von Foerster Heinz. Las Semillas de la Cibernetica. Barcelona, ES: Gedisa; 1991.

32. Sackett DL, Rosenberg IWMC, Muir Gray JA, Brian Haynes R, Richardson WS . Evidence based medicine: what it is and what it isn't - BMJ 1996;312:71-72

33. Spann S, Roa R, Augustovsky F. Medicina Basada en Pruebas (Paperback - Dic 2002). Houston: Department of Family Medicine. University of Baylor; 2002.

34. Leguiza J, Roa R.. Toma de decisiones en medicina. USA: Paperback; 2004.

35. Gorman, P., Information needs of physicians. J Am Soc Inf Sci 1995. 46(10): 729-736.

36. Souza, Alex Sander R; Mendes, Artur O. Abordagem Familiar. Grupo de Estudos en Saide da Familia. AMMFC: Belo Horizonte, 2007. Disponivel em http:// www.smmfc.org.br/gesf/gesf_abordagem.pdf [acesso em 10/09/2007].

37. Ibañez MG. Presentacion em el primer Congreso de Medicina General y Familiar. Cordoba. Argentina; 1999. 38. Asen KE, Tomson P. Intervención Familiar. Guia Práctica para los profesionales de la Salud. Barcelona: Paidós Ibérica SA; 1997.

39. Gilis AJ. Determinants of a health-promoting lifestyle: an integrative review. J Adv Nurs. 1993; 18(3): 345-353.

\section{Endereço para correspondência:}

25 de Mayo 808.

Cipolletti, Patagonia - Argentina

\section{Endereço eletrônico:}

ruben.roa@gmail.com 